\title{
Application of multi-criteria decision making methods for selection of micro-EDM process parameters
}

\author{
A. P. Tiwary • B. B. Pradhan · B. Bhattacharyya
}

Received: 4 September 2013/Accepted: 13 December 2013/Published online: 18 January 2014

(C) Shanghai University and Springer-Verlag Berlin Heidelberg 2014

\begin{abstract}
Ti-6Al-4V super alloy is an important engineering material with good strength to weight ratio and a wide range of applications in a number of engineering fields because of its excellent physical and mechanical properties. This work determines optimum process parameters such as pulse on time, peak current, gap voltage and flushing pressure, which influence the micro-electro discharge machining (EDM) process during machining of Ti-6Al-4V using combined methods of response surface methodology (RSM) and fuzzy-technique for order preference by similarity to ideal solution (TOPSIS). Central composite design (CCD) is used in the experimental investigation, and a decision making model is developed to identify the optimum process parameters in the microEDM process, which influence several machining criterions such as material removal rate (MRR), tool wear rate (TWR), overcut (OC) and taper. Triangular fuzzy numbers are used to determine the weighting factor for each process criterion. Further a fuzzy-TOPSIS method is used to select the most desirable factor level combinations. The proposed technique can be used to select optimal process parameters from various sets of combinations of process parameters in a micro-EDM process.
\end{abstract}

\footnotetext{
A. P. Tiwary · B. B. Pradhan $(\square)$

Department of Mechanical Engineering, Sikkim Manipal Institute of Technology, East Sikkim, Majitar 737136, India e-mail: bbpradhan1@ rediffmail.com

A. P. Tiwary

e-mail: aptiwary@gmail.com

B. Bhattacharyya

Department of Production Engineering, Jadavpur University,

Kolkata 700032, India

e-mail: bb13@rediffmail.com
}

Keywords Micro-EDM - Ti-6Al-4V · Fuzzy-technique for order preference by similarity to ideal solution (TOPSIS) · Micromachining

\section{Introduction}

The recent trend of research in the precision manufacturing world is the micro-machining of Ti-6Al-4V due to its classic properties of high corrosion resistant, high temperature resistant, high strength-to-weight ratio and its various ranges of applications in a diverse fields of engineering ranging from turbines, inkjet nozzles of printers, aerospace, automobile to biomedical, etc. However, Ti$6 \mathrm{Al}-4 \mathrm{~V}$ super alloy is a difficult-to-cut material, exhibits poor machinability for most of the conventional machining processes, especially during the drilling of micro-cavities and micro-through holes. Hence, micro-machining of titanium super alloy using non-traditional machining processes such as micro-electro discharge machining (micro-EDM) has been identified to be most appropriate machining technique since there is no involvement of mechanical forces during machining [1-3].

Micro-EDM is a noncontact type electro-thermo erosive process and thus there is no direct contact between the tool electrode and workpiece. Hence, the absence of machining forces to cause deformation of either workpiece or tool is an advantage. The material is removed by pulsed spark discharges generated at the inter electrode gap between two electrically conductive electrodes. Therefore, this process can be utilized to machine any electrically conducting materials irrespective of their strength, hardness and toughness. Micro-EDM is capable to machine a micro-hole to a depth equal to five times of the bore diameter. Moreover, micro-EDM systems available for commercial 
applications can machine a micro-hole and a micro-shaft as small as $5 \mu \mathrm{m}$ in diameter, and also a variety of complex three dimensional (3D) micro structures by minimizing the discharge pulse energy to the level of $10^{-7} \mathrm{~J}$ based on a precise mechanism with submicron accuracy [4, 5]. In addition, the surface roughness of the machined surface is quite good. This process is employed in manufacturing industries to produce the precision components like fuel injection nozzles used in diesel engines and also to make high precision masks used in micro electronics manufacturing systems (MEMS) [6, 7].

Micro-EDM has an enormous potential for machining a large range of advanced conductive materials due to its capability to machine any materials irrespective of the hardness, very small process forces involved during machining and good repeatability. These advantages of micro-EDM have made it the most potential candidate in micro-machining domain for achieving micro features of high-aspect-ratio. As such attempts have been made to study the tool wear and to develop the index for its wear compensation $[8,9]$.

However, a very few literature is available on the optimization of micro-EDM process parameters [10-12]. Using combined approach of response surface methodology (RSM) and fuzzy-technique for order preference by similarity to ideal solution (TOPSIS), there is virtually no research optimization available. Thus knowing the importance of this state-of-the-art machining process, an attempt has been made to develop a systematic approach for optimization of various micro-EDM process parameters such as peak current $\left(I_{\mathrm{p}}\right)$, pulse-on-time $\left(T_{\text {on }}\right)$, gap voltage $\left(V_{\mathrm{g}}\right)$ and flushing pressure $\left(P_{\mathrm{F}}\right)$ in order to improve the performance criteria of machined micro-hole like material removal rate (MRR), tool wear rate (TWR), overcut (OC) and taperness during EDM micro-machining of Ti-6Al-4V super alloy following fuzzy-TOPSIS approach.

\section{Decision making model for micro-EDM}

Micro-EDM is a thermo-erosive process involving various electrical and non-electrical process parameters which in turn affect the machining performance. To improve the machining criteria such as MRR, TWR, OC, taper and surface integrity the process needs to be studied in detail. The various micro-EDM process variables which influence the machining outputs are $T_{\mathrm{on}}, I_{\mathrm{p}}, V_{\mathrm{g}}$ and $P_{\mathrm{F}}[10]$.

The $T_{\text {on }}$ is the duration of pulse on time during which the electrical energy is supplied to the micro-electrode and the workpiece for machining. The duration of $T_{\text {on }}$ plays a very important role in machining performance. Apart from this, the $I_{\mathrm{p}}$ is another very important process parameter on which the machining efficiency depends. As such $I_{\mathrm{p}}$ has also been considered as another process parameter, the $V_{\mathrm{g}}$ and $P_{\mathrm{F}}$ also play very significant role in micro-EDM process. Higher is the $V_{\mathrm{g}}$, higher will be the inter-electrode gap, which directly affects the machining performance. Hence to study the effect of $V_{\mathrm{g}}$ on micro-EDM machining, this is considered as the third process parameter. Further, the cleaning of machining zone is a very important and difficult task. For effective cleaning of machining zone to facilitate smooth machining, flushing is required. Thus $P_{\mathrm{F}}$ has been considered as the fourth process parameter. The schematic planning of the decision making model based on four process parameters discussed above with the considered machining performances such as MRR, TWR, OC and taper is shown in Fig. 1.

\section{Micro-EDM performance measures}

The machining efficiency of micro-EDM process depends on several machining criterions such as MRR, TWR, OC and taper, etc. MRR is defined as the volume of material removal per unit time of machining and is expressed in $\mathrm{mm}^{3} / \mathrm{min}$ or $\mathrm{mg} / \mathrm{min}$. The difference in weight obtained by measuring the weight of workpiece before and after machining divided by the actual machining time gives the MRR. MRR directly depends on the pulse duration and the magnitude of peak current at the time of machining as it is directly related to the thermal energy produced during sparking which subsequently erodes the material from the workpiece by melting and vaporization. Higher value of MRR shows the higher efficiency of micro-EDM process. The erosion of tool material during machining is known as tool wear, which greatly affects the geometry of the machined micro-features, geometrical accuracy of micro-hole or micro-cavity. The volume of material eroded from tool per unit machining time is known as TWR, which is an important performance measure of the micro-EDM process. Lower value of TWR reflects the higher machining accuracy of microEDM process. Further, in micro-EDM process, it is observed that the diameter of machined micro-hole is always larger than the diameter of micro-tool used for machining. Hence, the difference in diameter between the micro-hole and the tool electrode is known as diameteral OC, and mathematically it can be expressed as

$O C=D_{\mathrm{I}}-D$,

where $D_{1}$ and $D$ are the diameters of micro-hole at entry and tool electrode respectively.

In micro-EDM process, the material is removed from the workpiece due to melting and vaporization at a very high temperature. This high temperature involved in the 


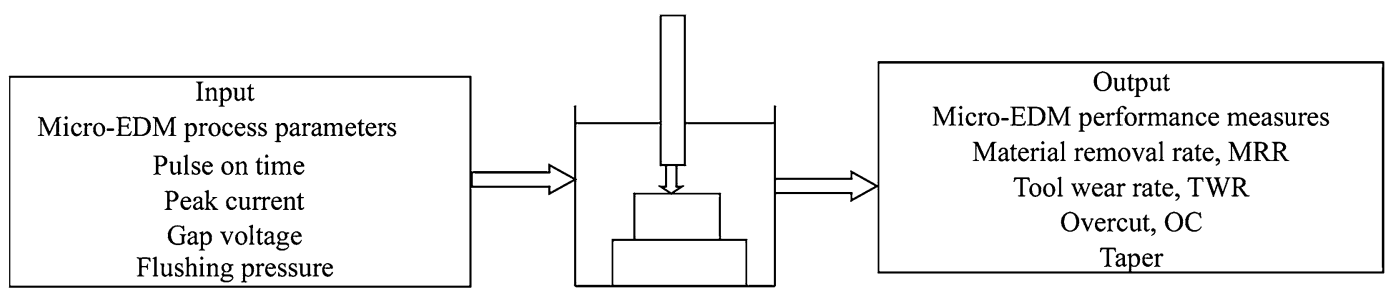

Fig. 1 Model for decision making in micro-EDM process

machining also affects the micro-tool used in machining and consequently the tool electrode wears out, causing the change in the shape of the tool and making it pointed at the tip, and generating the tapered micro-hole. This taperness (Taper) of the micro-hole can be calculated as

Taper $=\frac{D_{\mathrm{I}}-D_{\mathrm{o}}}{2 L}$,

where $D_{\mathrm{o}}$ is the diameter at exit, and $L$ is the length of the micro-hole.

\section{Experimental planning}

In the present research investigation, an attempt has been made to machine micro through-holes on titanium alloy of $1 \mathrm{~mm}$ thickness with the brass electrode of diameter $300 \mu \mathrm{m}$. Brass tool has been chosen as it is mostly used in industrial applications, and also it is more economical as compared to other electrodes used in micro-EDM. While carrying out the experimentations, for each experimental run new and identical tools have been used with positive polarity. The experiments have been carried out on an EDM machine (model S50 ZNC, manufactured by Sparkonix, India). The schematic diagram of EDM micromachining experimental set-up is shown in Fig. 2. The considered influencing micro-EDM process parameters were $I_{\mathrm{p}}, T_{\mathrm{on}}, P_{\mathrm{F}}$, and $V_{\mathrm{g}}$. These parameters were varied by keeping other machining parameters constant. The experimental design has been based on uniform rotatable central composite design (CCD) of RSM on the basis of four input factors mentioned above, having five levels of each one. In total, thirty-one experiments have been performed and at each experimental run, the experiment is performed three times. The average value of machining criteria is considered. This is done as micro-EDM process is stochastic in nature. The averages of the corresponding machining performances have been taken for further analyses. The schematic of micro-through hole on Ti-6Al-4V is shown in Fig. 3. Table 1 enlists the detailed experimental conditions and the process parameters, and their levels are shown in Table 2. Micro-EDM machining criteria during micro-hole machining on Ti-6Al-4V were calculated for each set of

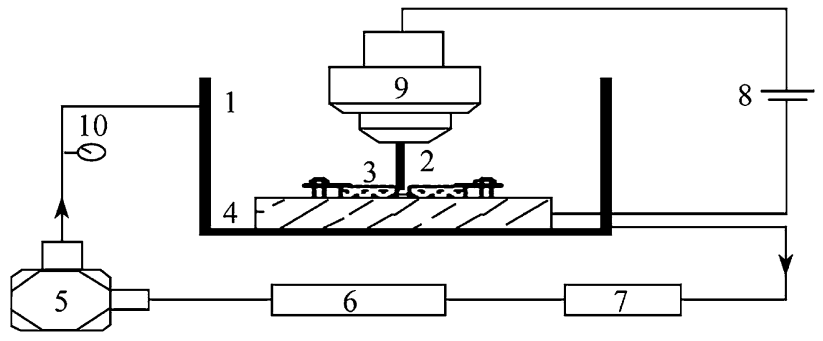

Fig. 2 Schematic of EDM micromachining experimental set-up. 1. Machining chamber filled with dielectric medium, 2. Tool electrode, 3. Work piece, 4. Work table, 5. Dielectric pump, 6. Dielectric reservoir, 7. Filter, 8. DC power supply, 9. Servo control, 10. Pressure gauge
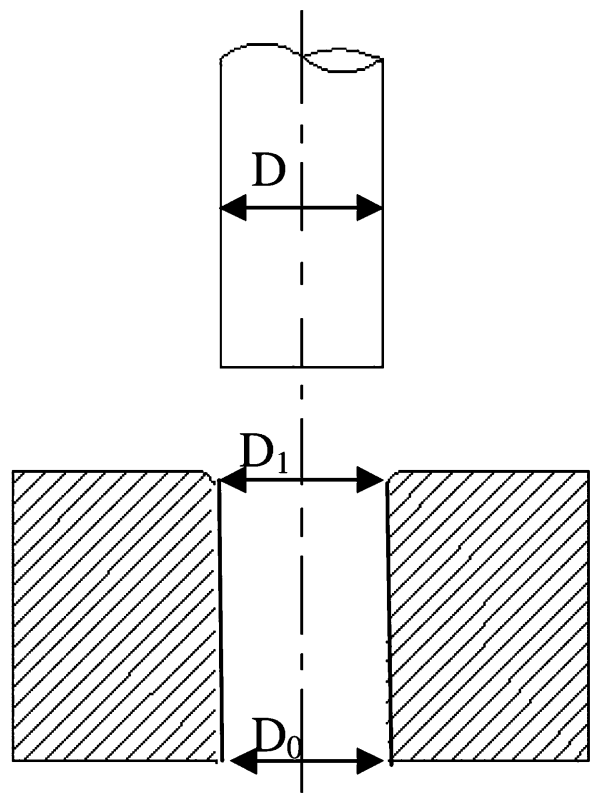

Fig. 3 Schematic of micro-hole generated from micro-EDM

experimental run based on experimental planning. In this research, MRR, TWR, OC and taper have been considered as micro-EDM process criteria of machined micro-through holes. MRR and TWR are estimated using the weight difference method by weighing each workpiece and tool respectively before and after machining per unit time. Weighing of workpiece and tool has been done by using a 
Table 1 Experimental condition for machining micro through hole on Ti-6Al-4V

\begin{tabular}{ll}
\hline Work condition & Description \\
\hline Work piece material & Ti-6Al-4V \\
Tool material & Brass $\Phi 300 \mu \mathrm{m}$ \\
Dielectric & DEF-92 oil \\
Polarity & Positive (workpiece: '+ve', tool: '-ve') \\
$I_{\mathrm{p}} / \mathrm{A}$ & $0.5-2.5$ \\
$T_{\mathrm{on}} / \mu \mathrm{s}$ & $1-16$ \\
$P_{\mathrm{f}} /\left(\mathrm{kg} \cdot \mathrm{cm}^{-2}\right)$ & $0.15-0.35$ \\
$V_{\mathrm{g}} / \mathrm{V}$ & $30-50$ \\
\hline
\end{tabular}

Table 2 Process parameters with their levels for micro-hole machining on Ti-6Al-4V

\begin{tabular}{llllll}
\hline Parameters & Levels & & & & \\
\cline { 2 - 6 } & Level 1 & Level 2 & Level 3 & Level 4 & Level 5 \\
\hline$T_{\text {on }} / \mu \mathrm{s}$ & 1 & 4 & 8 & 12 & 16 \\
$I_{\mathrm{p}} / \mathrm{A}$ & 0.5 & 1 & 1.5 & 2 & 2.5 \\
$V_{\mathrm{g}} / \mathrm{V}$ & 30 & 35 & 40 & 45 & 50 \\
$P_{\mathrm{f}} /\left(\mathrm{kg} \cdot \mathrm{cm}^{-2}\right)$ & 0.15 & 0.20 & 0.25 & 0.3 & 0.35 \\
\hline
\end{tabular}

precision weighing balance of METTLER TOLEDO, Switzerland having the least count of $0.01 \mathrm{mg}$. The diameters of each micro-hole at entry and exit have been measured using LEICA DM2500 optical precision measuring microscope at $5 \times$ magnification. The dimensions of the machined micro-holes were measured and recorded to evaluate the $\mathrm{OC}$ and taper. Table 3 enlists the process parametric combinations along with the corresponding machining criteria. These responses were further utilized for optimization using fuzzy-TOPSIS method for microEDM.

\section{Parametric analysis and optimization of micro-EDM process parameters}

Micro-EDM is an extremely complicated micromachining process, influenced by several process parameters, such as $T_{\text {on }}$, pulse-off-time $\left(T_{\text {off }}\right), I_{\mathrm{p}}, V_{\mathrm{g}}$, polarity $(p)$ and $P_{\mathrm{F}}$, etc. Since micro-EDM process is a complex function of above mentioned process parameters. Hence, it becomes very difficult to judiciously choose the combination of process parameters in order to obtain higher MRR, lower TWR, lower OC, and lower taper, i.e., optimal micro-EDM conditions under various process parametric combinations during micromachining operations that give control over geometrical accuracy and precision of the micro features.
Though many attempts have been made by the researchers globally to search out the optimal parametric combinations for micro-EDM process, but still lot of work has to be done for selection of optimal process parameters for achieving higher accuracy or higher machining efficiency. In most of the past researches MRR, TWR and tool wear compensation have been discussed. However, a very few research work has been reported on the modeling and optimization of the process variables for EDM in micromachining domain [11, 12]. But using combined approach of RSM and fuzzy-TOPSIS, there is virtually no research optimization available. In the present research paper, an attempt has been made to develop a systematic approach for the optimization of various micro-EDM process parameters such as $I_{\mathrm{p}}, T_{\mathrm{on}}$, $V_{\mathrm{g}}$ and $P_{\mathrm{F}}$ on the performance criteria of machined micro-hole, i.e., MRR, TWR, OC and taperness during micro-EDM of Ti-6Al-4V super alloy following fuzzyTOPSIS approach.

\section{Optimization using fuzzy TOPSIS method}

TOPSIS method proposed by Hwang and Yoon in 1981 is one of the suitable techniques to handle multi response problems in manufacturing applications. The basic concept of this method is to identify the best alternative or appropriate alternative that has the shortest distance from the positive ideal solution and the farthest distance from negative ideal solution. The positive ideal solution is a solution that maximizes the benefit criteria and minimizes adverse criteria, whereas the negative ideal solution minimizes the benefit criteria and maximizes the adverse criteria [13-17]. In the present study, maximizing MRR and minimizing TWR, OC and taper are considered as the objectives.

In this study, $31 \times 4$ performance matrix was prepared based on the experimental results enlisted in Table 3 given as

$\boldsymbol{A}=\left[\boldsymbol{a}_{\boldsymbol{m} n}\right]$,

where $m=1,2,3, \ldots, 31$ is the No. of experimental run, and $n=1,2,3,4$ is the No. of performance parameters.

The important weights for each performance parameters were assigned by a suitable linguistic variables described by triangular fuzzy numbers in the interval of $[0 ; 1]$ as shown in Table 4. A committee consisting of four members was constituted to act as a decision makers. Each performance parameter was rated by the decision makers with suitable weightage in their opinion with respect to linguistic term as given in Table 5 and 
Table 3 Process parametric combinations with experimental results based on uniform rotatable CCD

\begin{tabular}{|c|c|c|c|c|c|c|c|c|}
\hline Expt. No. & $T_{\mathrm{on}} / \mu \mathrm{s}$ & $I_{\mathrm{p}} / \mathrm{A}$ & $V_{\mathrm{g}} / \mathrm{V}$ & $P_{\mathrm{f}} /\left(\mathrm{kg} \cdot \mathrm{cm}^{-2}\right)$ & $\mathrm{MRR} /\left(\mathrm{mg} \cdot \min ^{-1}\right)$ & $\mathrm{TWR} /\left(\mathrm{mg} \cdot \mathrm{min}^{-1}\right)$ & $\mathrm{OC} / \mathrm{mm}$ & Taper \\
\hline 1 & 8 & 1.5 & 40 & 0.25 & 0.042222 & 0.023548 & 0.09400 & 0.002161 \\
\hline 2 & 1 & 1.5 & 40 & 0.25 & 0.025079 & 0.024961 & 0.07750 & 0.004570 \\
\hline 3 & 4 & 2.0 & 35 & 0.20 & 0.049035 & 0.024197 & 0.07810 & 0.002240 \\
\hline 4 & 12 & 1.0 & 35 & 0.20 & 0.025431 & 0.021262 & 0.08100 & 0.002314 \\
\hline 5 & 4 & 1.0 & 45 & 0.30 & 0.012255 & 0.030170 & 0.07500 & 0.005016 \\
\hline 6 & 12 & 2.0 & 45 & 0.30 & 0.029174 & 0.022018 & 0.08200 & 0.001236 \\
\hline 7 & 8 & 1.5 & 40 & 0.25 & 0.045261 & 0.023017 & 0.09500 & 0.002285 \\
\hline 8 & 4 & 2.0 & 45 & 0.20 & 0.066706 & 0.019288 & 0.09300 & 0.002695 \\
\hline 9 & 8 & 1.5 & 40 & 0.35 & 0.060853 & 0.018180 & 0.09100 & 0.002672 \\
\hline 10 & 8 & 1.5 & 40 & 0.15 & 0.076863 & 0.021765 & 0.10450 & 0.002460 \\
\hline 11 & 8 & 2.5 & 40 & 0.25 & 0.023858 & 0.021646 & 0.09050 & 0.001039 \\
\hline 12 & 8 & 1.5 & 40 & 0.25 & 0.043277 & 0.022767 & 0.09500 & 0.002147 \\
\hline 13 & 12 & 1.0 & 45 & 0.30 & 0.024197 & 0.014873 & 0.07250 & 0.003420 \\
\hline 14 & 4 & 1.0 & 35 & 0.30 & 0.048875 & 0.019916 & 0.08350 & 0.004437 \\
\hline 15 & 16 & 1.5 & 40 & 0.25 & 0.030000 & 0.019695 & 0.08400 & 0.003262 \\
\hline 16 & 8 & 1.5 & 40 & 0.25 & 0.044680 & 0.023922 & 0.09530 & 0.002072 \\
\hline 17 & 8 & 1.5 & 40 & 0.25 & 0.040844 & 0.023790 & 0.09450 & 0.002180 \\
\hline 18 & 12 & 2.0 & 35 & 0.30 & 0.029243 & 0.019207 & 0.10800 & 0.000449 \\
\hline 19 & 12 & 2.0 & 35 & 0.20 & 0.044382 & 0.033146 & 0.09300 & 0.001247 \\
\hline 20 & 8 & 0.5 & 40 & 0.25 & 0.002001 & 0.013977 & 0.08750 & 0.004120 \\
\hline 21 & 8 & 1.5 & 30 & 0.25 & 0.042817 & 0.022920 & 0.09400 & 0.000224 \\
\hline 22 & 4 & 1.0 & 45 & 0.20 & 0.008790 & 0.018898 & 0.11300 & 0.004170 \\
\hline 23 & 4 & 2.0 & 35 & 0.30 & 0.017548 & 0.016898 & 0.08900 & 0.002912 \\
\hline 24 & 4 & 2.0 & 45 & 0.30 & 0.015584 & 0.025914 & 0.07500 & 0.002942 \\
\hline 25 & 8 & 1.5 & 50 & 0.25 & 0.024866 & 0.022484 & 0.09800 & 0.002101 \\
\hline 26 & 12 & 1.0 & 35 & 0.30 & 0.064020 & 0.010506 & 0.08950 & 0.002202 \\
\hline 27 & 12 & 2.0 & 45 & 0.20 & 0.072514 & 0.021395 & 0.10125 & 0.002196 \\
\hline 28 & 8 & 1.5 & 40 & 0.25 & 0.045852 & 0.023142 & 0.09480 & 0.002126 \\
\hline 29 & 8 & 1.5 & 40 & 0.25 & 0.043211 & 0.022702 & 0.09500 & 0.002013 \\
\hline 30 & 12 & 1.0 & 45 & 0.20 & 0.012752 & 0.010601 & 0.10700 & 0.004048 \\
\hline 31 & 4 & 1.0 & 35 & 0.20 & 0.019231 & 0.023573 & 0.07850 & 0.002964 \\
\hline
\end{tabular}

Table 4 Linguistic variables described by triangular fuzzy numbers for the important weight of each performance parameters

\begin{tabular}{ll}
\hline Importance & Fuzzy weight \\
\hline Lowest (L1) & $(0,0,0.1)$ \\
Lower (L2) & $(0,0.1,0.3)$ \\
Low (L3) & $(0.1,0.3,0.5)$ \\
Medium (M) & $(0.3,0.5,0.7)$ \\
High (H3) & $(0.5,0.7,0.9)$ \\
Higher (H2) & $(0.7,0.9,1)$ \\
Highest (H1) & $(0.9,1,1)$ \\
\hline
\end{tabular}

aggregated fuzzy weight of performance parameters are given in Table 6.

A normalized performance matrix was developed using the equation given as
Table 5 Importance of machining responses

\begin{tabular}{lllll}
\hline Machining response & \multicolumn{4}{l}{ Decision makers } \\
\cline { 2 - 5 } & DM1 & DM2 & DM3 & DM4 \\
\hline MRR & H1 & H3 & H2 & H1 \\
TWR & L1 & L2 & L2 & L3 \\
OC & M & L3 & L2 & L1 \\
Taper & L3 & L1 & L2 & M \\
\hline \multirow{2}{*}{$x_{m n}=\frac{a_{m n}}{\sqrt{\sum_{m=1}^{31} a_{m n}^{2}}}$} & & & & \\
& & & & \\
\end{tabular}

where $a_{m n}$ represents the actual value of $m$-th attribute of $n$ th experimental run, and $x_{m n}$ represents the corresponding normalized value. 
Table 6 Aggregated fuzzy weights of performance parameters

\begin{tabular}{ll}
\hline Machining response & Fuzzy weight \\
\hline MRR & $0.75,0.9,0.975$ \\
TWR & $0.025,0.125,0.3$ \\
OC & $0.1,0.225,0.4$ \\
Taper & $0.1,0.225,0.4$ \\
\hline
\end{tabular}

The normalized performance matrix obtained as discussed above was then multiplied by the corresponding fuzzy weights as given in Table 6, and three different weighted performance matrices were developed. From the weighted performance matrices, the positive ideal value set $H^{+}$and the negative ideal value set $H$ were expressed as

$$
\begin{aligned}
H^{+}= & \left\{\left[\max \left(h_{m n}\right) \mid n \in M\right] \text { or }\left[\min \left(h_{m n}\right) \mid n \in M^{\prime}\right],\right. \\
& m=1,2,3, \cdots, 31\} \\
= & \left\{h_{1}^{+}, h_{2}^{+}, \cdots, h_{31}^{+}\right\}, \\
H^{-}= & \left\{\left[\min \left(h_{m n}\right) \mid n \in M\right] \text { or }\left[\max \left(h_{m n}\right) \mid n \in M^{\prime}\right],\right. \\
& m=1,2, \cdots, 31\} \\
= & \left\{h_{1}^{-}, h_{2}^{-}, \cdots, h_{31}^{-}\right\},
\end{aligned}
$$

where $M=\{1,2,3,4\}$ and $M^{\prime}=\{1,2,3,4\} . M$ and $M^{\prime}$ are associated with higher the better and lower the better performance parameters respectively. The performance parameter MRR considered in the study was higher the better type and other parameters like TWR, OC and taper were considered as lower the better type. In accordance to the weighted normalized fuzzy decision matrix, the elements $h_{m n}$ were normalized positive triangular fuzzy numbers and their ranges belong to the closed interval $[0 ; 1]$.

The accuracy of experimental result can also be estimated with respect to the positive and negative ideal solutions. Thus the distance of each experimental result from positive and negative ideal solutions were calculated with the help of the following equations:

$d_{m}^{+}=\sum_{n=1}^{4} d\left(h_{m n}, h_{n}^{+}\right), m=1,2, \cdots, 31$,

$d_{m}^{-}=\sum_{n=1}^{4} d\left(h_{m n}, h_{n}^{-}\right), m=1,2, \cdots, 31$.

This distance between two triangular fuzzy numbers was calculated using the following equation:

$d(x, y)=\sqrt{\frac{1}{3}\left(\left(x_{1}-y_{1}\right)^{2}+\left(x_{2}-y_{2}\right)^{2}+\left(x_{3}-y_{3}\right)^{2}\right)}$.

\begin{tabular}{|c|c|c|c|c|c|}
\hline Expt. no. & $T_{\mathrm{on}} / \mu \mathrm{s}$ & $I_{\mathrm{p}} / \mathrm{A}$ & $V_{\mathrm{g}} / \mathrm{V}$ & $P_{\mathrm{f}} /\left(\mathrm{kg} \mathrm{cm}^{-2}\right)$ & $\begin{array}{l}\text { Closeness } \\
\text { coefficient }\end{array}$ \\
\hline 1 & 8 & 1.5 & 40 & 0.25 & 0.6358559 \\
\hline 2 & 1 & 1.5 & 40 & 0.25 & 0.1997044 \\
\hline 3 & 4 & 2.0 & 35 & 0.20 & 0.6114745 \\
\hline 4 & 12 & 1.0 & 35 & 0.20 & 0.4031093 \\
\hline 5 & 4 & 1.0 & 45 & 0.30 & 0.1505216 \\
\hline 6 & 12 & 2.0 & 45 & 0.30 & 0.4763780 \\
\hline 7 & 8 & 1.5 & 40 & 0.25 & 0.6588643 \\
\hline 8 & 4 & 2.0 & 45 & 0.20 & 0.7512712 \\
\hline 9 & 8 & 1.5 & 40 & 0.35 & 0.7060501 \\
\hline 10 & 8 & 1.5 & 40 & 0.15 & 0.8288204 \\
\hline 11 & 8 & 2.5 & 40 & 0.25 & 0.5272391 \\
\hline 12 & 8 & 1.5 & 40 & 0.25 & 0.6474971 \\
\hline 13 & 12 & 1.0 & 45 & 0.30 & 0.3810745 \\
\hline 14 & 4 & 1.0 & 35 & 0.30 & 0.5299948 \\
\hline 15 & 16 & 1.5 & 40 & 0.25 & 0.4078319 \\
\hline 16 & 8 & 1.5 & 40 & 0.25 & 0.5585914 \\
\hline 17 & 8 & 1.5 & 40 & 0.25 & 0.6211865 \\
\hline 18 & 12 & 2.0 & 35 & 0.30 & 0.4865274 \\
\hline 19 & 12 & 2.0 & 35 & 0.20 & 0.5586944 \\
\hline 20 & 8 & 0.5 & 40 & 0.25 & 0.2375662 \\
\hline 21 & 8 & 1.5 & 30 & 0.25 & 0.6217904 \\
\hline 22 & 4 & 1.0 & 45 & 0.20 & 0.1469409 \\
\hline 23 & 4 & 2.0 & 35 & 0.30 & 0.3138306 \\
\hline 24 & 4 & 2.0 & 45 & 0.30 & 0.2797478 \\
\hline 25 & 8 & 1.5 & 50 & 0.25 & 0.4809710 \\
\hline 26 & 12 & 1.0 & 35 & 0.30 & 0.7832410 \\
\hline 27 & 12 & 2.0 & 45 & 0.20 & 0.8057609 \\
\hline 28 & 8 & 1.5 & 40 & 0.25 & 0.5704065 \\
\hline 29 & 8 & 1.5 & 40 & 0.25 & 0.6325558 \\
\hline 30 & 12 & 1.0 & 45 & 0.20 & 0.2250968 \\
\hline 31 & 4 & 1.0 & 35 & 0.20 & 0.3157893 \\
\hline
\end{tabular}

The proximity of a particular experimental run to the ideal solution was estimated using the closeness coefficient $C_{C_{0}}$ as shown in Eq. (10)
Table 7 Closeness coefficients at each parametric combination

$C_{C_{\mathrm{O}}}=\frac{d_{\mathrm{m}^{-}}}{d_{\mathrm{m}^{-}}+d_{\mathrm{m}^{+}}}$.

\section{Results and discussion}

Table 7 enlists the closeness coefficients for each experimental run based on uniform rotatable central composite design. These closeness coefficients have been calculated as discussed in the previous section. In Table 7, the highest value of closeness coefficient observed is 0.8288204 , corresponding to experiment No. 10 at parametric setting of $T_{\mathrm{on}} 8 \mu \mathrm{s}, I_{\mathrm{p}} 1.5 \mathrm{~A}, V_{\mathrm{g}} 40 \mathrm{~V}$ and $P_{\mathrm{F}} 0.15 \mathrm{~kg} / \mathrm{cm}^{2}$. Hence, the parametric setting, corresponding to experiment No. 10 is the optimal process parameter for micro-EDM process during micro-hole machining of Ti-6Al-4V among the 
Table 8 Response table for closeness coefficient at each level

\begin{tabular}{|c|c|c|c|c|c|c|}
\hline \multirow{2}{*}{$\begin{array}{l}\text { Process } \\
\text { parameters }\end{array}$} & \multicolumn{5}{|c|}{ Average closeness coefficients } & \multirow[t]{2}{*}{$\operatorname{Max}-\min$} \\
\hline & Level 1 & Level 2 & Level 3 & Level 4 & Level 5 & \\
\hline$T_{\text {on }}$ & 0.189704369 & 0.387446 & 0.594415 & 0.514985 & 0.407831903 & 0.404711 \\
\hline$I_{\mathrm{p}}$ & 0.137566241 & 0.366971 & 0.545394 & 0.535461 & 0.427239016 & 0.407828 \\
\hline$V_{\mathrm{g}}$ & 0.621790385 & 0.500333 & 0.511705 & 0.402099 & 0.380971045 & 0.240819 \\
\hline$P_{\mathrm{f}}$ & 0.828820391 & 0.477267 & 0.470774 & 0.425164 & 0.706050061 & 0.403656 \\
\hline
\end{tabular}

thirty one experiments as this has yielded the best multiperformance characteristics.

The average closeness coefficient for each level of the process parameters based on the CCD has been calculated by taking the average of the closeness coefficients at same factor level for each process parameters as shown in Table 8. Irrespective of the individual machining characteristics, a higher value of closeness coefficients represents the better performance at the corresponding parametric setting of various process parameters. Hence, the highest value of closeness coefficient has represented the optimal level of the combination of machining parameters. Based on the average closeness coefficients values enlisted in Table 8, the optimal machining performance for through micro-hole machining of Ti-6Al-4V has been obtained as $T_{\text {on }} 8 \mu$ s (level 3), $I_{\mathrm{p}} 1.5 \mathrm{~A}$ (level 3), $V_{\mathrm{g}} 30 \mathrm{~V}$ (level 1), and $P_{\mathrm{F}} 0.15 \mathrm{~kg} / \mathrm{cm}^{2}$ (level 1). The difference between the maximum and the minimum value of the average closeness coefficients of the micro-EDM process parameters have been obtained as 0.404711 for $T_{\mathrm{on}}, 0.407828$ for $I_{\mathrm{p}}$, 0.240819 for $V_{\mathrm{g}}$ and 0.403656 for $P_{\mathrm{F}}$.

Further, the difference of the maximum and minimum average closeness coefficients for various process parameters at all five levels has been compared to identify the most influencing micro-EDM process parameter in microhole machining of Ti-6Al-4V. This comparison showed the level of significance of the input process parameters over the output or multi-criteria characteristics. After the comparison it has been observed that the greatest value, i.e., 0.407828 corresponds to the $I_{\mathrm{p}}$. Hence, this indicates that the $I_{\mathrm{p}}$ is the most important micro-EDM process parameter and affects significantly on the multi-performance characteristics among all other process parameters. Based on the comparison, the preference of process parameters in this study can be ordered in terms of their importance as $I_{\mathrm{p}}, T_{\mathrm{on}}$, $P_{\mathrm{F}}$, and $V_{\mathrm{g}}$ with their corresponding closeness coefficient as $0.407828,0.404711,0.403656$, and 0.240819 respectively. The ranking of the parametric settings based on the closeness coefficients in descending order is presented in Table 9. The higher closeness coefficient of corresponding combination of process parameters indicates the better machining characteristics in micro-EDM of Ti-6Al-4V. The confirmation experiment at optimal parametric setting
Table 9 Ranking of the parametric settings based on the closeness coefficients in descending order

\begin{tabular}{|c|c|c|c|c|c|c|}
\hline $\begin{array}{l}\text { Expt. } \\
\text { No. }\end{array}$ & $T_{\mathrm{on}} / \mu \mathrm{s}$ & $I_{\mathrm{p}} / \mathrm{A}$ & $V_{\mathrm{g}} / \mathrm{V}$ & $P_{\mathrm{f}} /\left(\mathrm{kg} \mathrm{cm}^{-2}\right)$ & $\begin{array}{l}\text { Closeness } \\
\text { coefficients }\end{array}$ & Ranks \\
\hline 10 & 8 & 1.5 & 40 & 0.15 & 0.8288204 & 1 \\
\hline 27 & 12 & 2.0 & 45 & 0.2 & 0.8057609 & 2 \\
\hline 26 & 12 & 1.0 & 35 & 0.3 & 0.7832410 & 3 \\
\hline 8 & 4 & 2.0 & 45 & 0.2 & 0.7512712 & 4 \\
\hline 9 & 8 & 1.5 & 40 & 0.35 & 0.7060501 & 5 \\
\hline 7 & 8 & 1.5 & 40 & 0.25 & 0.6588643 & 6 \\
\hline 12 & 8 & 1.5 & 40 & 0.25 & 0.6474971 & 7 \\
\hline 1 & 8 & 1.5 & 40 & 0.25 & 0.6358559 & 8 \\
\hline 29 & 8 & 1.5 & 40 & 0.25 & 0.6325558 & 9 \\
\hline 21 & 8 & 1.5 & 30 & 0.25 & 0.6217904 & 10 \\
\hline 17 & 8 & 1.5 & 40 & 0.25 & 0.6211865 & 11 \\
\hline 3 & 4 & 2.0 & 35 & 0.2 & 0.6114745 & 12 \\
\hline 28 & 8 & 1.5 & 40 & 0.25 & 0.5704065 & 13 \\
\hline 19 & 12 & 2.0 & 35 & 0.2 & 0.5586944 & 14 \\
\hline 16 & 8 & 1.5 & 40 & 0.25 & 0.5585914 & 15 \\
\hline 14 & 4 & 1.0 & 35 & 0.3 & 0.5299948 & 16 \\
\hline 11 & 8 & 2.5 & 40 & 0.25 & 0.5272391 & 17 \\
\hline 18 & 12 & 2.0 & 35 & 0.3 & 0.4865274 & 18 \\
\hline 25 & 8 & 1.5 & 50 & 0.25 & 0.4809710 & 19 \\
\hline 6 & 12 & 2.0 & 45 & 0.3 & 0.4763780 & 20 \\
\hline 15 & 16 & 1.5 & 40 & 0.25 & 0.4078319 & 21 \\
\hline 4 & 12 & 1.0 & 35 & 0.2 & 0.4031093 & 22 \\
\hline 13 & 12 & 1.0 & 45 & 0.3 & 0.3810745 & 23 \\
\hline 31 & 4 & 1.0 & 35 & 0.2 & 0.3157893 & 24 \\
\hline 23 & 4 & 2.0 & 35 & 0.3 & 0.3138306 & 25 \\
\hline 24 & 4 & 2.0 & 45 & 0.3 & 0.2797478 & 26 \\
\hline 20 & 8 & 0.5 & 40 & 0.25 & 0.2375662 & 27 \\
\hline 30 & 12 & 1.0 & 45 & 0.2 & 0.2250968 & 28 \\
\hline 2 & 1 & 1.5 & 40 & 0.25 & 0.1997044 & 29 \\
\hline 5 & 4 & 1.0 & 45 & 0.3 & 0.1505216 & 30 \\
\hline 22 & 4 & 1.0 & 45 & 0.2 & 0.1469409 & 31 \\
\hline
\end{tabular}

has been conducted and is presented in Table 10. It is observed from Table 10 that the machining responses are close to machining responses of experiment No. 10 having the highest closeness coefficient, i.e., Rank 1. This corroborates the fact that the optimal parametric setting 
Table 10 Confirmation experimental result at optimal parametric setting

\begin{tabular}{|c|c|c|c|c|c|c|c|}
\hline$T_{\mathrm{on}} / \mu \mathrm{s}$ & $I_{\mathrm{p}} / \mathrm{A}$ & $V_{\mathrm{g}} / \mathrm{V}$ & $P_{\mathrm{f}} /\left(\mathrm{kg} \mathrm{cm}^{-2}\right)$ & $\mathrm{MRR} /\left(\mathrm{mg} \min ^{-1}\right)$ & $\mathrm{TWR} /\left(\mathrm{mg} \mathrm{min}^{-1}\right)$ & $\mathrm{OC} / \mathrm{mm}$ & Taper \\
\hline 8 & 1.5 & 30 & 0.15 & 0.076780 & 0.021691 & 0.01023 & 0.00243 \\
\hline
\end{tabular}

searched out through fuzzy-TOPSIS yielded the optimal responses and is in close agreement to the parametric setting with the highest closeness coefficient value.

\section{Conclusions}

In the present research work, an attempt has been made to carry out micro-EDM on Ti-6Al-4V super alloy. Based on the DOE, the experimentations were carried out and the machining responses were observed. To determine the optimum process parameters, such as $T_{\mathrm{on}}, I_{\mathrm{p}}, V_{\mathrm{g}}$ and $P_{\mathrm{F}}$, which influence the micro-EDM process during machining of Ti-6Al-4V, combined methods of RSM and fuzzyTOPSIS were used.

(i) Triangular fuzzy numbers has been used to determine the weighting factors for each process criteria and TOPSIS method has been used to select the most desirable factor level combinations.

(ii) A model for decision making has been successfully developed in order to identify the optimum process parameters in micro-EDM process, which influence several machining criterion such as MRR, TWR, OC and taper.

(iii) Based on the analysis of closeness coefficients, the optimal machining performance for the through micro-hole machining of Ti-6Al-4V has been obtained as $8 \mu$ s of $T_{\text {on }}$ (level 3), $1.5 \mathrm{~A}$ of $I_{\mathrm{p}}$ (level 3), $30 \mathrm{~V}$ of $V_{\mathrm{g}}$ (level 1), and $0.15 \mathrm{~kg} / \mathrm{cm}^{2}$ of $P_{\mathrm{F}}$ (level 1). Further analysis has indicated that the peak current is the most important micro-EDM process parameter and affects significantly on the multi-performance characteristics among all other process parameters.

(iv) The order of micro-EDM process parameters considered in the present study in terms of their importance has been observed as $I_{\mathrm{p}}, T_{\mathrm{on}}, P_{\mathrm{F}}$ and $V_{\mathrm{g}}$ with their corresponding closeness coefficient as 0.407828 , $0.404711,0.403656$ and 0.240819 respectively. This developed technique can be used to select the optimal process parameters from various sets of combinations of process parameters of micro-EDM process.

Thus the outcome of this research can be utilized in micro manufacturing industries and other researches to improve the geometrical accuracy and precision of the machined through micro-hole.

\section{References}

1. Pradhan BB, Bhattacharyya B (2008) Improvement in microhole machining accuracy by polarity changing technique for microelectrode discharge machining on Ti-6Al-4V. Proc IMechE B 222(2):163-173

2. Pradhan BB, Masanta M, Sarkar BR et al (2009) Investigation on electro-discharge micromachining of Titanium super alloy. Int $\mathbf{J}$ Adv Manuf Technol 11-12:1094-1106

3. Kao JY, Tsao CC, Wang SS et al (2010) Optimization of the EDM parameters on machining Ti-6Al-4V with multiple quality characteristics. Int J Adv Manuf Technol 47:395-402

4. Masuzawa T (2000) State-of-the-art of micromachining. Ann CIRP 49(2):473-488

5. Liu K, Lauwers B, Reynaerts D (2010) Process capabilities of micro-EDM and its applications. Int $\mathrm{J}$ Adv Manuf Technol 47:11-19

6. Allen DM, Lecheheb A (1996) Micro electo-discharge machining of ink jet nozzle: optimum selection of material and machining parameter. J Mater Process Technol 58(1):53-63

7. Yeo SH, Yap GG (2001) A feasibility study on the micro electrodischarge machining process for photomask fabrication. Int J Adv Manuf Technol 18:7-11

8. Tsai YY, Masuzawa T (2004) An index to evaluate the wear resistance of the electrode in micro-EDM. J Mater Process Technol 149(1-3):304-309

9. Rahman MM, Khan MAR, Noor MM et al (2011) Optimization of machining parameters on surface roughness in EDM of Ti$6 \mathrm{Al}-4 \mathrm{~V}$ using Response surface method. Adv Mater Res 213:402-408

10. Pradhan BB, Bhattacharyya B (2009) Modelling of micro-electro discharge machining during machining of titanium alloy Ti-6Al$4 \mathrm{~V}$ using response surface methodology and artificial neural network algorithm. Proc IMechE B 223(6):683-693

11. Bigot S, Valentincic J, Blatnik O et al (2006) Micro-EDM parameters optimization. In: The 2nd international conference on multi-material micro manufacture, Grenoble, France, pp 20-22

12. Mustafa A, Ulas C, Ahmet H (2013) Optimization of micro-EDM drilling of inconel 718 super alloy. Int $\mathbf{J}$ Adv Manuf Technol 66(5-8):1015-1023

13. Hwang CL, Yoon K (1981) Multiple attribute decision makinga state-of-the-art survey. In: Economics and mathematical systems. Springer, Berlin, pp 128-139

14. Aiello G, Enea M, Galante G et al (2009) Clean agent selection approached by fuzzy TOPSIS decision-making method. Fire Technol 45:405-418

15. Bortolan G, Degani R (1985) A review of some methods for ranking fuzzy subset. Fuzzy Sets Syst 15(1):1-19

16. Tong LI, Su CT (1997) Optimizing multi-response problems in the Taguchi method by fuzzy multiple attribute decision making. Qual Reliab Eng Int 13(1):25-34

17. Santhi M, Ravikumar R, Jeyapaul R (2013) Optimization of process parameters in electro chemical machining (ECM) using DFA-fuzzy set theory-TOPSIS for titanium alloy. Multidiscip Model Mater Struct 9(2):243-255 